\title{
PENGARUH AKTIVITAS FISIK TERHADAP KEJADIAN HIPERTENSI PADA LAKI-LAKI DEWASA AWAL (18-40 TAHUN) DI WILAYAH PUSKESMAS BROMO MEDAN TAHUN 2017
}

\author{
Rina Andriani Harahap ${ }^{1}$, R. Kintoko Rochadi ${ }^{2}$, Sorimuda Sarumpaet ${ }^{3}$ \\ ${ }^{1}$ Mahasiswa Program Magister Ilmu Kesehatan Masyarakat, Universitas Sumatera Utara \\ rinaandrianiharahap@gmail.com \\ ${ }^{2,3}$ Dosen Program Magister Ilmu Kesehatan Masyarakat, Universitas Sumatera Utara
}

\begin{abstract}
ABSTRAK
Secara global sekitar 17 juta kematian pertahun akibat penyakit kardiovaskular, hampir sepertiga dari total penduduk dunia. Dari data tersebut, komplikasi dari hipertensi mengakibatkan 9,4 juta kematian setiap tahun. Prevalensi hipertensi di Indonesian yang didapat melalui pengukuran tekanan darah pada penduduk umur 18 tahun ke atas yaitu sebesar 25,8\%.Prevalensi hipertensi di Sumatera utara berdasarkan diagnosis oleh tenaga kesehatan sebesar 6,8\%. 31,7\% atau 1 dari 3 orang mengalami hipertensi. Sekitar 75\% penderita hipertensi tidak mengetahui bahwa dirinya menderita hipertensi. Mereka baru menyadari jika telah terjadi komplikasi. Di Indonesia, ancaman hipertensi tidak boleh diabaikan. Hal ini dapat dibuktikan dengan jumlah penderita hipertensi yang setiap waktu semakin bertambah. Penelitian ini bertujuan untuk melihat pengaruh aktivitas fisik terhadap kejadian hipertensi pada laki-laki dewasa awal (18-40 tahun) di wilayah Puskesmas Bromo Medan tahun 2017. Jenis penelitian ini adalah studi analitik observasional dengan menggunakan desain case control. Sampel padapenelitian sebanyak 44 kasus dan 44 kontrol yang ditetapkan secara consecutive sempling. Pengumpulan data dengan menggunakan kuesioner. Analisis data dilakukan secara univariat dan bivariat dengan menggunakan uji chi-square. Berdasarkan hasil penelitian menunjukkan terdapat pengaruh aktivitas fisik terhadap kejadian hipertensi pada laki-laki dewasa awal (18-40 tahun) dengan nilai p=0,010 OR= 3,095 (95\% CI: 1,292-7,417). Disimpulkan bahwa laki laki dewasa awal (18-40 tahun) yang beraktivitas fisik ringan memiliki perkiraan risiko 3 kali akan terkena hipertensi dibandingkan dengan yang beraktivitas fisik sedang dan berat.
\end{abstract}

Katakunci : hipertensi, aktivitas fisik, 18-40 tahun

\section{PENDAHULUAN}

\section{Latar Belakang}

Hipertensi atau tekanan darah tinggi adalah peningkatan tekanan darah sistolik lebih dari 140 mmHg dan tekanan darah diastolik lebih dari $90 \mathrm{mmHg}$ pada dua kali pengukuran dengan selang waktu lima menit dalam keadaan cukup istirahat/tenang. (Kemenkes, 2013). Secara global sekitar 17 juta kematian per tahun akibat penyakit kardiovaskular, hampir sepertiga dari total. Dari data tersebut, komplikasi dari hipertensi mengakibatkan 9,4 juta kematian setiap tahun di seluruh dunia, 45\% kematian akibat penyakit jantung dan 51\% kematian akibat stroke. Pada tahun 2008, di seluruh dunia, sekitar $40 \%$ dari orang dewasa berusia di atas 25 tahun telah didiagnosis menderita hipertensi. Jumlah penderita hipertensi naik dari 600 juta pada tahun 1980 menjadi 1 miliar pada tahun 2008 (WHO, 2013).

Menurut data Global Status Report on Noncommunicable Diseases 2010, dari World Health Organization (2013) prevalensi hipertensi tertinggi adalah di wilayah Afrika, yaitu 46\% dari orang dewasa berusia di atas 25 tahun, sedangkan prevalensi terendah, yaitu 35\% di Amerika. Prevalensi hipertensi di Indonesian berdasarkan data Riskesdas tahun 2013 yang didapat melalui pengukuran tekanan darah pada penduduk umur 18 tahun ke atas yaitu sebesar 25,8\% (Kemenkes, 2013). Prevalensi hipertensi di Sumatera utara berdasarkandiagnosis oleh tenaga kesehatan sebesar 6,8\%. 31,7\% atau 1 dari 3 orang mengalami hipertensi. Sekitar $75 \%$ penderita hipertensi tidak mengetahui bahwa dirinya menderita hipertensi. Mereka baru menyadari jika telah terjadi komplikasi. Meningkatnya prevalensi hipertensi dikaitkan dengan pertumbuhan penduduk, penuaan dan faktor risiko perilaku, seperti diet tidak sehat, merokok, mengkonsumsi alkohol, kurangnya aktivitas fisik, kelebihan berat badan dan stress yang terus-menerus. 
Aktivitas fisik secara teratur bermanfaat dalam mengatur berat badan dan menguatkansistem jantung dan pembuluh darah. Kurangnya aktifitas fisik dapat mengakibatkan seseorang terkena hipertensi. Berdasarkan data Riskesdas 2007 terlihat bahwa sebagian besar penduduk di Provinsi Sumatera Utara yang kurang melakukan aktivitas fisik masih lebih banyak $(51,9 \%)$. Bahkan di Kota Medan penduduk yang kurang melakukan aktivitas fisik mencapai (62,2\%). Aktivitas fisik merupakan salah satu faktor risiko terjadinya hipertensi.

Secara teori aktivitas fisik sangat memengaruhi stabilitas tekanan darah. Pada orang yang tidak aktif melakukan kegiatan cenderung mempunyai frekuensi denyut jantung yang lebih tinggi. Hal tersebut mengakibatkan otot jantung bekerja lebih keras pada setiap kontraksi. Makin keras otot jantung dalam memompa darah, makin besar pula tekanan darah yang membebankan pada dinding arteti sehingga tahanan perifer yang menyebabkan kenanikan tekanan darah. Kurang nya aktivitas fisik juga dapat meningkatkan risiko kelebihan berat badan yang akan menyebkan risiko hipertensi meningkat (Triyanto, 2014).

\section{Rumusan Masalah}

Hipertensi merupakan salah satu penyakit yang prevalensinya terus mengalami peningkatan di dunia. Jumlah kasus hipertensi di wilayah Puskesmas Bromo Medan tiga tahun terakhir mengalami peningkatan. Penyakithipertensi merupakan salah satu dari 10 penyakit tertinggi di Puskesmas Bromo Medan berdasarkan pada Laporan Sistem Pencatatan dan Pelaporan tingkat Puskesmas (SP2TP). Peningkatan tekanan darah yang berlangsung dalam jangka waktu lama (persisten)dapat menyebabkan komplikasi medis seperti kerusakan pada ginjal (gagal ginjal), jantung (penyakit jantung koroner) dan otak (menyebabkan stroke) bila tidak dideteksi secara dini dan mendapat pengobatan yang memadai. Berdasarkan hal tersebut maka yang menjadi permasalahan pada penelitian ini adalah apakah ada pengaruh aktivitas fisik terhadap kejadian hipertensi pada laki-laki dewasa awal (18-40 tahun) di wilayah Puskesmas Bromo Medan Tahun 2017.

\section{MATERI DAN METODE PENELITIAN Defenisi hipertensi}

Defenisi hipertensi atau tekanan darah adalah peningkatan tekanan darah sistolik lebih dari 140 $\mathrm{mmHg}$ dan atau tekanan darah diastolik lebih dari $90 \mathrm{mmHg}$ pada dua kali pengukuran dengan selang waktu lima menit dalam keadaan cukup istirahat/tenang (Kemenkes, 2014).

Klasifikasi hipertensimenurutJoint National Committee (JNC7), Lee Kennedy (2009)

Tabel 1. Klasifikasi Hepertensi Untuk Orang Dewasa

\begin{tabular}{lcc}
\hline & \multicolumn{2}{c}{ Klasifikasi HipertensiUntuk Orang Dewasa } \\
\cline { 2 - 3 } & Tekanan darah & Tekanan darah \\
& Systolik $(\mathrm{mmHg})$ & Diastolik $(\mathrm{mmHg})$ \\
\hline Normal & $<120$ & $<80$ \\
Prehipertensi & $120-139$ & $80-89$ \\
HipertensiStage 1 & $140-159$ & $90-99$ \\
HipertensiStage 2 & $160-179$ & $100-109$ \\
HipertensiStage 3 & $\geq 180$ & $\geq 110$ \\
\hline
\end{tabular}

Sumber: joint national committe on prevation detection, evaluation, and treatment of hight blood pressure VII/JNC-VII. (2009). 


\section{Defenisi aktivitas fisik}

Aktivitas fisik adalah setiap gerakan tubuh yang dihasilkan oleh otot rangka yang memerlukan pengeluaran energi. Kurangnya aktivitas fisikmerupakan faktor risiko untuk penyakit kronis, dan secara keseluruhan diperkirakan menyebabkan kematian secara global ( WHO, 2010).

\section{Pengukuran aktivitas fisik}

Menurut FAO/WHO/UNU (2001), besarnya aktivitas fisik yang dilakukan seseorang selama 24 jam dinyatakan dalam Physical Activity Level (PAL).

PAL ditentukan dengan rumus:

$$
=\frac{\sum(\quad P A R \times W \quad)}{24}
$$

Kategori tingkat aktivitas Physical Activity Level (PAL) dibedakan menjadi tiga, yaitu aktivitas ringan, sedang dan berat.

1. Aktivitas fisik ringan(sedentary lifestyle) memiliki nilai PAL antara 1,40-1,69. Seseorang yang mempunyai aktivitas ringan menggunakan kendaraan untuk transportasi, tidak berolahraga, dan cenderung meluangkan waktu hanya untuk kegiatan yang dilakukan hanya dengan duduk dan berdiri, dengan sedikit gerakan tubuh.

2. Aktivitas fisik sedang (active or moderately active lifestyle) memiliki nilai PAL 1,70-1,99. Seseorang yang mempunyai tingkat aktivitas sedang tidak memerlukan energi yang besar, namun kebutuhan energi pada kegiatan ini lebih tinggi daripada kegiatan aktivitas ringan.

3. Aktivitas fisik berat(vigorous or vigorously active lifestyle) memiliki nilai PAL 2,00-2,40. Aktivitas berat dilakukan oleh seseorang yang melakukan kerja berat dalam waktu yang lama.

\section{Jenis Penelitian}

Penelitian ini merupakan studi analitikobservasional dengan menggunakan disaincase control studybersifat retrospective yang bertujuan untuk mengetahui pengaruhaktivitas fisikterhadap kejadian hipertensi pada laki-laki dewasa awal 18-40 tahun).

\section{Populasi (Subyek Penelitian)}

Populasi kasus pada penelitian ini adalah seluruh laki-laki dewasa awal (18-40 tahun) yang telah didiagnosis menderita hipertensi di wilayah Puskesmas Bromo Medan. Dan populasi kontrol pada penelitian ini adalah seluruh laki-laki dewasa awal (18-40 tahun) yang telah didiagnosis tidak menderita hipertensi di wilayah Puskesmas Bromo Medan.

\section{Besar Sampel}

Besar sampel diambil dengan rumus studi kasus kontrol dengan perhitungan sebagai berikut (Sastroasmoro, 2016) :

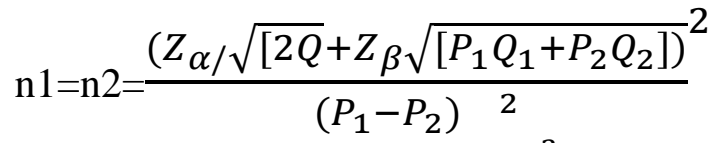

$$
\begin{aligned}
& \mathrm{n}=\left[\frac{1,96 \sqrt{0,41}+0,84 \sqrt{0,36}}{0,07}\right]^{2} \\
& \mathrm{n}=43,7=44
\end{aligned}
$$


Berdasarkan hasil perhitungan diperoleh sampel 44 orang. Penelitian ini menggunakan perbandingan kasus dan kontrol 1:1, maka sampel kasus dalam penelitian ini sebanyak 44 orang dan sampel kontrol sebanyak 44 orang. Total keseluruhan sampel sebanyak 88 orang.Kriteria inklusi pada sampel kasusadalah laki-laki dewasa awal (18-40 tahun) yang menderita hipertensi berdasarkan diagnosa pada rekam medik. Kriteria eksklusi sampel kasus yaitu laki-laki dewasa awal yang mengalami komplikasi penyakit (ginjal, jantung, dan diabetes.Kriteria inklusi pada sampel kontrol adalah laki-laki dewasa awal (18-40 tahun) yang tidak menderita hipertensi berdasarkan diagnosa pada rekam medik. Kriteria eksklusi sampel kontrolyaitulaki-laki dewasa awal yang mengkonsumsi obat hipertensi.

\section{Teknik Pengambilan Sampel}

Teknik sampel dalam penelitian ini adalah Non probablity sampling (consecutive sempling) yaitu suatu teknik penetapan sampel diantara populasi sesuai dengan yang dikehendaki peneliti (Nursalam, 2008).Alasan peneliti untuk menjadikan consecutive sempling dalam penelitian ini karena keterbatasan sampel penelitian untuk kasus dan kontrol.

\section{HASIL DAN PEMBAHASAN}

Tabel 2. Distribusi Frekuensi Aktivitas Fisik Penderita Hipertensi Pada Laki-laki Dewasa Awal di Wilayah Puskesmas BromoMedan Tahun 2017

\begin{tabular}{lcccc}
\hline \multicolumn{1}{c}{ Variabel } & \multicolumn{4}{c}{ Kejadian Hipertensi } \\
\cline { 2 - 5 } & & Kasus & \multicolumn{3}{c}{ Kontrol } \\
\hline Aktivitas fisik & $\mathbf{n}$ & $\mathbf{0}$ & $\mathbf{n}$ & $\mathbf{\%}$ \\
Ringan & 30 & 68,2 & 18 & 40,9 \\
Sedang & 8 & 18,2 & 14 & 31,8 \\
Berat & 6 & 13,6 & 12 & 27,3 \\
\hline Total & $\mathbf{4 4}$ & $\mathbf{1 0 0}$ & $\mathbf{4 4}$ & $\mathbf{1 0 0}$ \\
\hline
\end{tabular}

Berdasarkan tabel diatas didapatkan hasil analisis univariat diperoleh distribusi frekuensi aktivitas fisik pada kelompok kasus sebanyak 30 orang $(68,2 \%)$ yang beraktivitas fisik ringan, 8 orang $(18,2 \%)$ yang beraktivitas fisik sedang, 6 orang $(13,6 \%)$ yang beraktivitas fisik berat. Sedangkan pada kelopok kontrol sebanyak 18 orang $(40,9 \%)$ yang beraktivitas fisik ringan, 14 orang $(31,8 \%)$ yang beraktivitas fisik sedang, 12 orang $(27,3 \%)$ yang beraktivitas fisik berat.

Tabel 3. Pengaruh Aktivitas Fisik Terhadap Kejadian Hipertensi Pada Laki-laki Dewasa Awal di Wilayah Puskesmas BromoMedan Tahun 2017

\begin{tabular}{|c|c|c|c|c|c|c|}
\hline \multirow{3}{*}{$\begin{array}{c}\text { Variabel } \\
\text { Aktivitas fisik }\end{array}$} & \multicolumn{4}{|c|}{ Kejadian Hipertensi } & \multirow{3}{*}{$P$ value } & \multirow{3}{*}{$\begin{array}{c}\text { OR } \\
95 \% \mathrm{CI}\end{array}$} \\
\hline & \multicolumn{2}{|c|}{ Kasus } & \multicolumn{2}{|c|}{ Kontrol } & & \\
\hline & $\mathrm{n}$ & $\%$ & $\mathbf{n}$ & $\%$ & & \\
\hline Ringan & 30 & 68,2 & 18 & 40,9 & & 3,095 \\
\hline Sedang dan berat & 14 & 31,8 & 26 & 59,1 & 0,010 & $1,292-7,417$ \\
\hline Total & 44 & 100 & 44 & 100 & & \\
\hline
\end{tabular}


Berdasarkan tabel di atas didapatkan hasil analisis bivariat dengan menggunakan uji Chi-square, pada kelompok kasus sebanyak 30 orang $(68,2 \%)$ laki-laki dewasa awal yang memiliki aktivitas fisik ringan dan 14 orang $(31,8 \%)$ laki-laki dewasa awal yang memiliki aktivitas fisik sedang dan berat. Sedangkan pada kelompok kontrol terdapat sebanyak 18 orang $(40,9 \%)$ laki-laki dewasa awal yang memiliki aktivitas fisik ringan dan 26 orang $(59,1 \%)$ laki-laki dewasa awal yang memiliki aktivitas fisik sedang dan berat. Hasil uji statistik menunjukkan bahwa terdapat pengaruh aktivitas fisik terhadap kejadian hipertensi $(p=0,010)$ pada taraf nyata $\alpha=0,05$ hasil penelitian juga menunjukkan nilai $\mathrm{OR}=3,095$ (95\%CI 1,292-7,417), artinya laki-laki dewasa awal yang beraktivitas fisik ringan perkiraan resikonya 3 kali akan menderita hipertensi dibanding dengan yang beraktivitas fisik sedang dan berat.

Hal ini sejalan dengan penelitian yang dilakukan Atun, dkk (2014) yang menunjukkan ada hubungan yang signifikan antara aktivitas fisik dengan kejadian hipertensi, dengan nilai $\mathrm{OR}=$ 4,69 $(95 \% \mathrm{CI}=1,12-19,67)$ yang berarti bahwa orang dengan aktivitas fisik ringan memiliki peluang atau risiko 4,69 kali akan menderita hipertensi dibandingkan dengan yangberaktivitas sedang. Demikian juga penelitian yang dilakukan Anggraeni, dkk (2013), di Kota Makassar tentang faktor risiko kejadian hipertensi dengan nilai $\mathrm{OR}=1,57$ (95\% CI=0,81-3,03), dimana aktivitas fisik terbukti sebagai faktor risiko terjadinya hipertensi. Hal tersebut berarti bahwa orang yang kurang beraktivitas fisik ringan beresiko 1,57 kali akan menderita hipertensi dibandingkan dengan yang beraktivitas fisik berat. Penelitian yang dilakukan Ilyasa,dkk (2013) dalam penelitiannya juga menyimpulkan bahwa aktivitas fisik berhubungan dengan kejadian hipertensi dengan nilai $(p=0,002 ; \mathrm{OR}=4,449)$.

Aktivitas fisik sangat memengaruhi stabilitas tekanan darah. Pada orang yang tidak aktif melakukan kegiatan fisik cenderung mempunyai frekuensi denyut jantung yang lebih tinggi. Hal tersebut mengakibatkan otot jantung bekerja lebih keras pada setiap kontraksi. Makin keras usaha otot jantung dalam memompa darah, makin besar pula tekanan darah yang dibebankan pada dinding arteri sehingga tahanan perifer yang menyebabkan kenaikan tekanan darah. Kurangnya aktivitas fisik juga dapat meningkatkan risiko kelebihan berat badan yang akan menyebabkan risiko hipertensi meningkat (Triyanto, 2014).

\section{KESIMPULAN DAN SARAN}

Berdasarkan hasil penelitian yang telah dilakukan dapat diambil kesimpulan bahwa terdapat pengaruh aktivitas fisik terhadap kejadian hipertensi. Dimana laki-laki dewasa awal yang beraktivitas fisik ringan beresiko menderita hipertensi dibanding dengan yang beraktivitas fisik sedang dan berat. Saran peneliti untuk kedepannya bagi puskesmas agar lebih meningkatkan peran serta Posbindu PTM (Pos Pembinaan Terpadu Penyakit Tidak Menular) dalam masyarakat, seperti membuat kegiatan olahraga bersama sebaiknya bukan hanya dilakukan jika ada kegiatansaja, namun perlu dilakukan rutin setiap minggunya, melakukan penyuluhan pada laki-laki dewasa awal tentang pentingnya aktivitas fisik bagi kesehatan, dan juga melibatkan keluarga terdekat agar lebih menekankan mereka untuk menghindari faktor risiko terjadinya hipertensi.

\section{Ucapan TerimaKasih}

Penulis mengucapkan terima kasih kepada kepala Puskesmas Bromo Medan yang telah memberikan dukungan terhadap penelitian ini. 


\section{REFERENSI}

Anggraeni,R., Wahiduddin, Rismayanti, 2013. Faktor Risiko Aktivitas Fisik, Merokok, dan Konsumsi Alkohol terhadap Kejadian Hipertensi Pada Lansia di Wilayah Kerja PuskesmasPattingalloang Kota Makassar.Universitas Hasanuddin.

Atun,T., Siswati, T., Kurdanti, W., 2014. Asupan Sumber Natrium, Rasio Kalium, Aktivitas Fiisk dan Tekanan Darah Pasien Hipertensi. Yogyakarta: Politekhnik Kemenkes Yogyakarta.

FAO/WHO/UNU, 2001. Human Energy Requirement, Report of a Joint FAO/WHO/UNU Expert Consultation. Rome.

Ilyasa,F., G., Abduh, R., Indah, B., 2013. Hubungan antara Obesitas, Pola Makan, Aktivitas Fisik, Merokok, dan Lama Tidur dengan Kejadian Hipertensi pada Lansia (Studi Kasus di Desa Limbung Dusun Mulyorejo dan Sido Mulyo Posyandu Bunda Kabupaten Kubu Raya).FIK UMP.

Kemenkes RI, 2013. Buletin Jendela Data dan Informasi Kesehatan Penyakit Tidak Menular, Jakarta. 2013. Riset Kesehatan Dasar, Jakarta: Diakses 10 April 2017; http://www. depkes.go.id

Kemenkes, 2014. Data dan Informasi Kesehatan Provinsi Sumatera Utara.Diakses10April2017.;http://www.depkes.go.id/download.php?file=download/pusda tin/kunjungan kerja/sumut/20des\%014.pdf.

Nursalam. 2008. Konsep dan Penerapan Metodologi Penelitian Ilmu Keperawatan, Jakarta : Salemba Medika.

Riskesdas, 2007. Laporan Riset Kesehatan Dasar Provinsi Sumatera Utara, Jakarta: Diakses10 April 2017; http://.depkes.co.id

Sastroasmoro, Sudigdo., Ismael Sofyan, 2016. Dasar-Dasar Metodologi Penelitian Klinis Edisi ke 5 Revisi, Jakarta : CV. Sagung Seto.

Trinyanto, E, 2014. Pelayanan Keperwatan Bagi Penderita Hipertensi Secara Terpadu, Yogyakarta: Graha Ilmu.

WHO,2010. Physical Activity. In Guide to Community Preventive Service.

WHO,2013. A Global Biefton Hypertension. Diakses 10 april 2017; http://iskworld.com/downloads/pdf/global_bieft_hypertension.pdf 